\title{
Emergence and Control of Antibiotic-resistant Gram-negative Bacilli in Older Adults
}

\author{
Dror Marchaim • David E. Katz • L. Silvia Munoz-Price
}

Published online: 30 June 2013

(C) Springer Science+Business Media New York 2013

\begin{abstract}
The prevalence of multidrug resistant Gramnegative organisms is increasing worldwide. The Infectious Diseases Society of America has previously singled out groups of pathogens with the highest threat, the majority of which are Gram-negative bacilli. These isolates are prevalent not only in intensive-care units of acute-care facilities, but are also found among residents of long-term care facilities with various levels of care, and occasionally among patients without exposure to healthcare systems. Advanced age is an independent predictor for carriage of many of these organisms, and elderly patients are subjected to worse outcomes following the acquisition of resistant Gram-negatives. Due to their frequent admissions and transfers across different healthcare facilities within a region, the elderly constitute important epidemiological reservoirs for these bacteria. Containing the acquisitions of resistant Gramnegatives among the elderly could be achieved through reduction of either 1) selective pressure (e.g. less antibiotics) or 2) colonization pressure (e.g. less exposure to resistant bacteria). This manuscript will review the present situation of multidrug resistant Gram-negative organisms, especially among the elderly, and the infection control interventions that might mitigate their further spread.
\end{abstract}

D. Marchaim

Division of Infectious Diseases, Assaf Harofeh Medical Center, Zerifin, Israel

D. Marchaim

Sackler School of Medicine, Tel-Aviv University, Tel-Aviv, Israel

D. E. Katz

Department of Internal Medicine D, Shaare Zedek Medical Center, Jerusalem, Israel

\section{S. Munoz-Price $(\triangle)$}

Departments of Medicine, Public Health Sciences,

and Anesthesiology, University of Miami, PPW L-302, 1611 N.W.

12th Avenue, Miami, FL 33136, USA

e-mail: smunozprice@med.miami.edu
Keywords Elderly · Antimicrobial resistance $\cdot$ MDRO . Aging $\cdot$ Multidrug resistance

\section{Introduction}

There is a continuing rise in the incidence of infections caused by multidrug resistant Gram-negative organisms in acute-care hospitals, outpatient healthcare facilities, and even in purely community settings $[1-5,6 \bullet \cdot]$. These organisms can be resistant to all commercially available antibiotics, including carbapenems (e.g. imipenem, meropenem) and polymixins (e.g. colistin). The elderly are specifically prone to infection caused by resistant Gram-negative organisms, and many of these pathogens are endemic to United States' (US) long-term care facilities (LTCF) [3, 7-10]. This worrisome trend is evident not just in the US, but worldwide [11, 12]. Multidrug resistant organisms (MDRO) lead to devastating outcomes among individuals [7, 13], and on a broader level, pose an eminent threat to public health $[14,15]$. Older adults are particularly prone to poor outcomes following MDRO infections $[6 \bullet \bullet, 8$, 9, 16-18]. The Infectious Disease Society of America (IDSA) has listed groups of pathogens that pose the highest threat due to increments in prevalence and lack of effective therapeutics [1]. These are known as the "ESKAPE" pathogens, i.e. pathogens that currently cause the majority of hospital infections and effectively "escape" the effects of available antibacterial drugs [1].

The ESKAPE pathogens are composed mostly of Gramnegative bacilli: i.e. Pseudomonas aeruginosa, Acinetobacter baumannii, and various beta-lactamases (including carbapenemases) producing Enterobacteriaceae (Klebsiella pneumoniae, Enterobacter species, Escherichia coli) [1]. Their mechanisms of resistance include not only hydrolyzing enzymes, but also porin mutations and hyper-expression of efflux pumps (Fig. 1). Gram-positives pathogens are also listed as part of the ESKAPE pathogens, and include 
Fig. 1 Mechanisms of betalactam resistance among Gramnegative bacilli. The mechanisms of beta-lactam resistance among Gram-negative bacteria include: 1) enzymes that destroy betalactams (e.g. beta-lactamases, carbapenemases), 2) porin mutations which preclude the entry of antibiotics into bacteria, 3) hyper-expression of efflux pumps that expel antibiotics outside the bacteria, and 4) mutations of penicillin binding proteins (PBP). From MunozPrice LS, Weinstein RA.

Acinetobacter infection. $N$ Engl $J$ Med 2008 Mar

20;358(12):1271-81. Copyright (C) 2008 Massachusetts Medical Society. Reprinted with permission from Massachusetts Medical Society

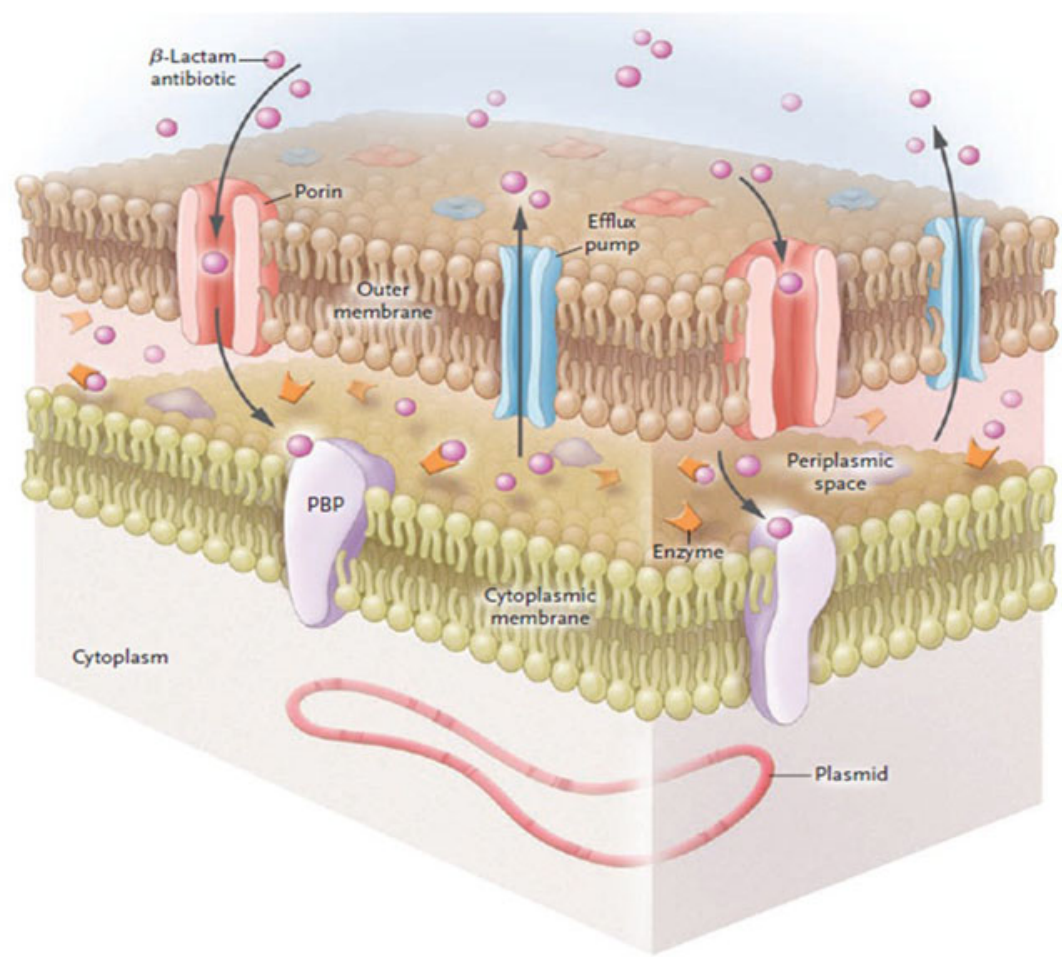

methicilllin-resistant Staphylococcus aureus (MRSA) and vancomycin-resistant enterococci (VRE); however, Gramnegatives pose a greater threat $[7,9]$. This is in part due to the lack of success in bringing new drugs to the market with activity against Gram-negative MDROs [1]. This is in contrast to new and novel agents that have been developed for treating MRSA and VRE infections [7].

\section{Pseudomonas aeruginosa and Acinetobacter baumannii}

P. aeruginosa and A. baumannii, are common human pathogens associated with high rates of morbidity and mortality [19-22]. Both pathogens are frequent causes of healthcareassociated pneumonia and hospital-acquired pneumonia (including ventilator-associated pneumonia), as well as other infectious syndromes [23]. Age is an independent predictor for carriage of these pathogens in the hospital settings, and older age is associated with increased mortality from these infections $[19,20,24,25]$. The recent major epidemiological shifts of these infections are related to the development of antibiotic resistance [26] (Table 1) and their detection outside of the intensive-care unit (ICU) setting. Infections are now being observed in lower acuity (e.g., step-down units) locations in hospitals and in ambulatory healthcare settings, including LTCFs [16, 26, 27]. The prevalence of carbapenem-resistant A. baumannii increased from $<1 \%$ of all $A$. baumannii isolations in 2003 to $58 \%$ in 2009 in one US acute care facility [26]. This trend has been reported from multiple additional facilities in the US [23] and worldwide [12]. Frequently, the only available agents to treat these carbapenem-resistant isolates (both A. baumannii and P. aeruginosa) are 1) polymixins, i.e. colistin and polymixin $b$, which are highly toxic [28] and poorly determined efficacy; 2) some aminoglycosides, which are also toxic and inappropriate as single agents for most infectious clinical syndromes [29]; and 3) tigecycline (only for A. baumannii, not for $P$. aeruginosa), which is unsuitable for severe invasive bloodstream infections due to its low serum levels [30] and resistance rates [7, 22, 31-33] (Table 1).

\section{The Enterobacteriaceae: Escherichia coli, Klebsiella pneumoniae, and Enterobacter Species}

\section{Extended-Spectrum Beta-Lactamases (ESBLs)}

The spread of common enteric pathogens such as E. coli, $K$. pneumoniae, and Enterobacter species, which are resistant to a wide range of antimicrobials, is an additional serious threat that has emerged in the past decade [1,7]. ESBL-producing Enterobacteriaceae (Table 1) were initially isolated from ICU patients of acute-care facilities [34], but now have spread to ambulatory settings [5, 35] and LTCFs. Furthermore, they have been isolated from previously healthy patients who had no documented contact to healthcare environments or procedures, and who had not recently consumed antibiotics [36, 37]. However, advanced age has been identified as an independent risk factor for ESBL infection in multiple reports [5, 35, 38].

ESBL-producing Enterobacteriaceae are frequently co-resistant to additional classes of antimicrobials, e.g. fluoroquinolones 


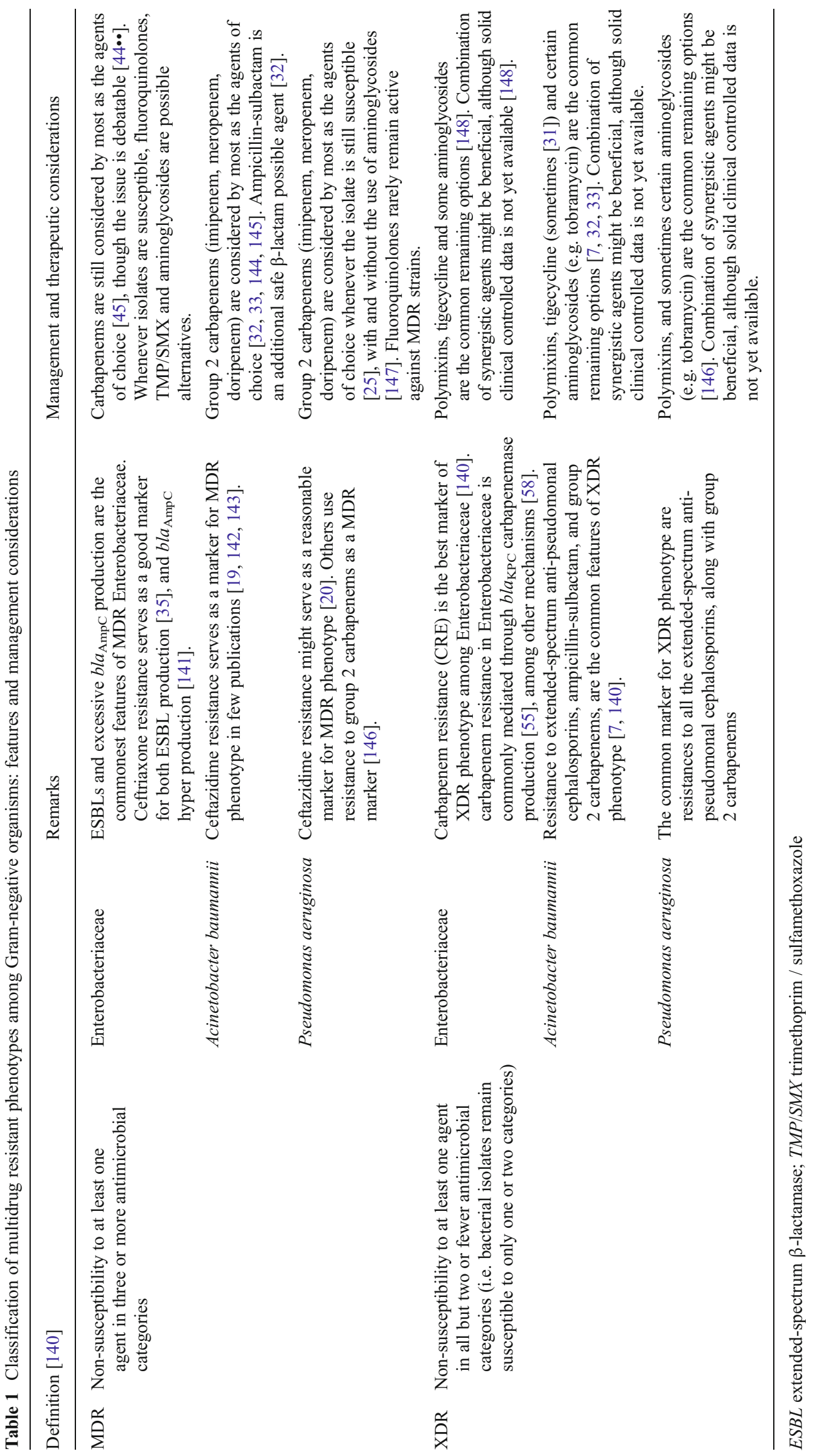


and trimethoprim-sulfamethoxazole, and therefore there is frequently no oral therapeutic options to treat these infections [39] (Table 1). ESBL infections are frequently being managed only with parenteral agents, with all their associated complications and patients' safety issues [5]. Fosfomycin might be a potential oral therapeutic option for ESBLproducing isolates [40]. However, this agent is only approved for simple urinary tract infections [41], and there is lack of controlled data pertaining to its efficacy for ESBL infections $[42 \bullet, 43]$. Despite conflicting recent data [44••], carbapenems are still considered by most as the agents of choice for treating ESBL infections [39, 45] (Table 1).

\section{Carbapenem-Resistant Enterobacteriaceae (CRE)}

An important issue contributing to resistance among Enterobacteriaceae is the emergence and spread of strains resistant to carbapenems [4]. The elderly are particularly prone to develop CRE infections [46-48]. Therapeutics for CRE are scarce and are limited to polymixins, tigecycline, and sometimes aminoglycosides [49, 50] (Table 1). The mortality rate among bacteremic cases is $\sim 70 \%$ [51], and the median time to initiation of appropriate therapy among these patients is $\sim 100$ hours, i.e. these patients suffer from significant delays in initiation of appropriate antimicrobial therapy [29]. Due to the frequent transfer of patients among facilities within a region, multidrug resistant Gram-negative organisms have spread to LTCFs and long-term acute care hospitals (LTACHs). These facilities constitute important part of the continuum of care and seem to play an important role in the further spread of organisms within a geographical area $[16,52 \bullet \bullet]$.

The most prevalent carbapenemase in the US [53] and abroad [54] is Klebsiella pneumoniae carbapenemase (KPC), mainly produced by K. pneumoniae [55], E. coli [55] and Enterobacter species [56]. Additional carbapenemases reported in the US, Asia, and Europe are the metallo- $\beta$-lactamases [57]. Recently, the New-Delhi metallo- $\beta$-lactamase (NDM), which originated in the Indian sub-continent, has spread worldwide [58], including sporadic cases in the US [59]. Antibiotic exposure is one of the major independent predictors for acquisition of CRE [47]. Given the paucity of therapeutic options, infection control measures and antimicrobial stewardship efforts are our main line of defense against these highly resistant strains.

\section{Risk Factors for Acquisition of Multidrug Resistant Gram-negatives Among the Elderly}

As previously stated, the elderly are prone to infection by multidrug resistant Gram-negative organisms $[60,61]$, including $P$. aeruginosa [17, 62-65], A. baumannii [19, 66, 67], ESBL-producing Enterobacteriaceae [5, 68], and CREs
$[46,48,69]$. However, these data are likely biased, and it would be more reasonable to assume that older age is a confounder rather than a real predictor for acquisition of MDROs; this is because elderly are more often 1) institutionalized (permanently or for prolonged periods), 2) have higher severity and amount of co-morbidities $[65,70,71], 3)$ have declines in functional status (i.e. incontinence), 4) have deteriorated consciousness, 5) have external foreign invasive devices (e.g. central lines, urinary catheters, mechanical ventilation) [65], 6) more often are going through invasive procedures [65], 7) suffer from acquired immunosuppressive states (apart from the immunosenescence associated with normal aging $[65,72-75])$, and 8 ) receive relatively more antibiotics, which leads to acquisition of MDROs through induction of selective pressure $[9,10,47,65,76,77]$. Since these aforementioned variables represent independent predictors for acquisition of MDROs [19, 20, 47, 48, 61], advanced age might represent a confounder in these analyses. Although age is not a modifiable variable, studies that aim to prevent acquisition of these strains among the elderly are warranted as they represent a population at risk for acquisition and infection by MDROs [19, 47, 78].

\section{Infection Control Issues at LTCFs}

For the most part, infection control research is geared to acute care hospitals, and thus targets groups of patients with higher case mix indexes and shorter lengths of stay. Therefore, infection control at LCTFs has primarily constituted an extrapolation of interventions implemented at acute care hospitals, with some modifications. However, the resources available to acute care hospitals, for both personnel and assets, are far superior than the limited means available to the majority of nursing homes. This precarious situation is further aggravated by the current healthcare circumstances, which encourage acute care hospitals to discharge patients earlier in their hospitalization, subsequently increasing the severity of illness of the patients admitted to chronic settings, including nursing homes [10].

In a previous review on the topic, Mody described the challenges of infection control programs at LCTFs as: 1) structural (sub-optimal nursing staffing, high turnover of staff, variable acuity of illness among residents, and limited availability to patient's laboratory data), 2) process factors (variable staff education, limited use or availability of diagnostic tests, and constrained use of quality indicators and regional databases), and 3) host factors [79]. Nursing home residents are at a particular high risk of colonization with MDROs due to their age, comorbidities, and frequent transfers to and from acute care hospitals with resulting high antibiotic exposures [80॰]. However, the significance of acquisition of MDROs among nursing home residents has been 
previously questioned [81]. Nevertheless, nursing home residents, due to their frequent healthcare facility transfers, can carry and spread MDROs throughout different healthcare facilities of a geographical region [6*0]. In 2008, a series of acute care hospitals, long-term acute care hospitals, and nursing homes were involved in the regional spread of KPC-producing K. pneumoniae [6••]. Transfer of unknown colonized patients among facilities was one of the main reasons for the rapid emergence of this organism within the region. A similar experience was recently described in Israel; in this country, a multicenter, national survey, detected a large unrecognized proportion of nursing home residents as carriers of carbapenem-resistant $K$. pneumoniae. Interestingly, but not surprisingly, this study showed that different long-term care facilities had different prevalence rates of colonization, i.e. rehabilitation centers had the lowest prevalence (3\%), and skilled wards had the highest prevalence rates $(25 \%)$ [82•].

Due to host factors among their residents and the prolonged length of stays at LTCFs, infection control practices usually done at acute care settings are particularly challenging to implement in chronic settings. Nevertheless, infection control programs at LCTFs are needed and required by the Centers for Medicare and Medicaid. According to the 2008's SHEA/APIC infection control guidelines at LCTFs, infection control programs should have an Infection Control Committee (with core and ad hoc members) and an infection preventionist; these guidelines also delineate the roles of the infection control program at LTCFs [83]. In general, infection control programs serve several functions, including surveillance of hospital acquired infections and acquisition of MDROs, prevention of infections, control of outbreaks, creation and implementation of policies, and education of both staff and patients on infection control practices [79].

Even though the roles of infection control programs have been clearly identified by the above guidelines, not all facilities comply with these recommendations. Castle and colleagues reviewed the rate of deficiency citations given to nursing homes over the period of 2000 and 2007 [84]. They found that in average $15 \%$ of all nursing homes received citations during the study period, although most of these citations were not critical. More importantly, the rate of citations was noted to increase from $12.8 \%$ in 2000 to $17.3 \%$ in 2007 [84]. Therefore, LTCFs constitute healthcare institutions with major opportunities for improvement in infection control.

In acute care hospitals, infection control interventions geared to preventing transmission of resistant Gramnegative organisms across patients include contact precautions, increased hand hygiene, identification of asymptomatic carriers, physical separation (i.e. cohorting) of MDRO carriers from non-carriers (in some cases using dedicated nursing staff), and environmental disinfection (Table 2).
Table 2 Infection control interventions

1. Increase hand hygiene compliance

2. Contact isolation of MDRO-positive patients (bedridden)

3. Use of single rooms for MDRO-positive

4. Cohorting MDRO-positive patients (ideally with the same type of MDRO)

5. Improving environmental cleaning

6. Optimizing transitions of care

$M D R O$ multidrug resistant organisms

These interventions are geared to affect the three major pathways of transmission of MDROs from carriers to noncarriers: healthcare worker hands, shared equipment, and contaminated environment (Fig. 2). However, these interventions are challenging to translate to LTCFs due to their unique characteristics; mainly long length of stays (months or years) among patients with high mobility (not bedridden) and with multiple opportunities of social interactions in common areas (e.g. dining room, lounge areas, gym).

There are some infection control topics pertaining to resistant Gram-negative organisms that deserve special attention:

- Contact Precautions in Long-Term Care Facilities: Contact precautions is usually defined as the use of gowns and gloves upon entry to a patient's room. Contact precautions constitute one of the main interventions for preventing transmission of resistant organisms among institutionalized patients. However, most of the literature on MDROs in nursing homes focuses on prevention of Gram-positive organisms (e.g. MRSA) rather than Gram-negatives. Furthermore, data on the effectiveness of contact precautions at LTCFs is currently lacking. Moreover, the mental and psychological consequences of long-term isolation have not been studied $[85,86]$.

In 2004, Trick and collaborators compared routine glove use versus contact isolation precautions based on MDRO status. These investigators found no difference

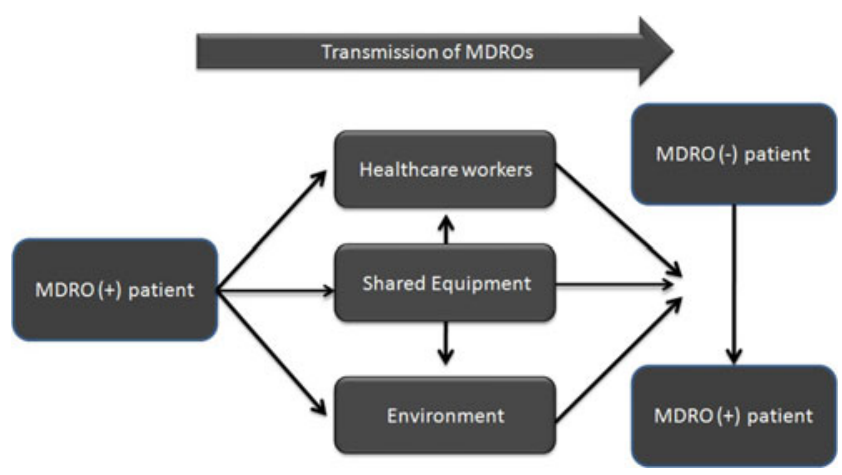

Fig. 2 Main pathways of patient-to-patient transmission of multidrug resistant organisms (MDRO) 
in acquisition of neither MRSA nor VRE between the intervention and control groups [87]. The authors suggested that universal glove use might provide a feasible alternative to the usual contact isolation practices practiced in acute care settings. However, there are no such controlled data pertaining to multidrug resistant Gram-negative organisms.

The 2008 SHEA/APIC guidelines for infection control in LTCFs recommends the use of contact precautions only among residents colonized or infected with MDROs that are ill and fully dependent on staff for daily activities or if secretions cannot be contained [83]. These guidelines also encourage the use of single rooms for MDRO colonized individuals; alternatively, cohorting of rooms with other residents (ideally colonized with the same MDRO) is recommended. As a last choice, a room could be shared between an MDRO colonized resident and a "low risk" MDRO negative resident [83]. An interesting and novel approach was postulated in 2011 in which LTCF residents would be targeted for enhanced contact precautions based on the presence of indwelling catheters rather than on colonization with MDROs [88].

In summary, even though there is a potential risk for patient-to-patient transmission of resistant Gram-negative organisms, confinement of mobile residents to their rooms due to their MDRO status should be discouraged. Additionally, contact precautions should be reserved for a small subset of MDRO colonized residents.

- Hand Hygiene: Hand hygiene is one of the most effective and least expensive infection control interventions in healthcare. However, compliance with hand hygiene among health care workers is far from ideal [89]. Most studies looking at hand hygiene interventions have been performed in acute care settings and only few had been performed at LTCFs. A Canadian study measured the hand hygiene compliance of the staff at two LTCFs, finding an overall compliance rate of $14.7 \%$ out of 459 hand hygiene opportunities. Not having a sink in the room significantly decreased compliance with hand hygiene (0 \% vs. $15.7 \%, p=0.02$ ) [90]. Similarly, an Italian study found an adherence with proper hand hygiene practices of only $17.5 \%$ (54 out of 308 opportunities) [91].

In 2003, Mody and colleagues evaluated the hand hygiene theoretic knowledge levels of LTCFs' staff before and after the introduction of a waterless alcohol-based hand rub and an education program [92]. The authors found increased hand hygiene frequency in one of the two wards tested. Additionally, hand cultures performed among the health care workers found Gram-negative organisms in $66 \%$ of the hands cultured [92]. Ashraf and collaborators evaluated the knowledge, attitudes, and barriers related to hand hygiene at 17 LTCFs. Among 1,143 respondents, only a third was familiar with the CDC hand hygiene guidelines, being the main barrier to hand hygiene the absence of alcohol-based hand rub or sinks [93].

In summary, promotion of hand hygiene at LTCFs constitutes an area with great potential for improvement. Furthermore, hand hygiene interventions should concentrate on both educational programs for the staff and increasing the availability of hand disinfectants.

- Transitions of Care: An important problem among the elderly derives from their higher frequency of interfacility transfers. In 2009, the rate of hospitalizations from nursing homes was 204.5 per 1,000 persons aged 65 years and older [94]. Transitions of care between nursing homes and other facilities (e.g. acute care hospitals, long-term acute care hospitals, rehabilitation centers) make elderly patients susceptible to care fragmentation, with a subsequent impact on their quality of care [80•]. This less than ideal communication between facilities has been detected as a contributing factor in the spread of resistant Gramnegatives within a region $[6 \bullet \bullet, 9]$. Additionally, the variability on isolation practices between facilities creates confusion in the management of the patient.

Therefore, transitions of care constitute another important area where major improvements can be made. Interventions at this level should include clear documentation upon interfacility transfers of any cultures with multidrug resistant Gram-negative organisms - bodily sources and dates - not just from the most recent admission, but also from previous healthcare stays. Obviously, this tracking of MDROs would be vastly facilitated by an integrated electronic microbiology database across healthcare facilities. In the meantime, we should concentrate in optimizing the documentation of MDRO carriage status across the continuum of care within a region [9].

- Environmental Disinfection: The healthcare environment constitutes a reservoir for MDROs in the acute care setting [95]. Furthermore, heightened cleaning of hospital surfaces has been associated to decreased acquisition of MDROs among patients [96]. There are several ways to determine the degree of cleaning in a facility. An easy and inexpensive way is by using ultraviolet markers in the form of a powder [97] or gel [98] (Fig. 3). After inconspicuous application on high touch surfaces (e.g. bed rails, bedside tables, drawers), the markers should be inspected using an ultraviolet lamp after at least 48 hours from application. Markers found present at 48 hours represent surfaces that have not been cleaned. These regular evaluations and feedback of cleaning should be used as part of a quality improvement process within the institution.

Murphy and colleagues used ultraviolet markers to evaluate the degree of cleaning at ten different LTCFs 


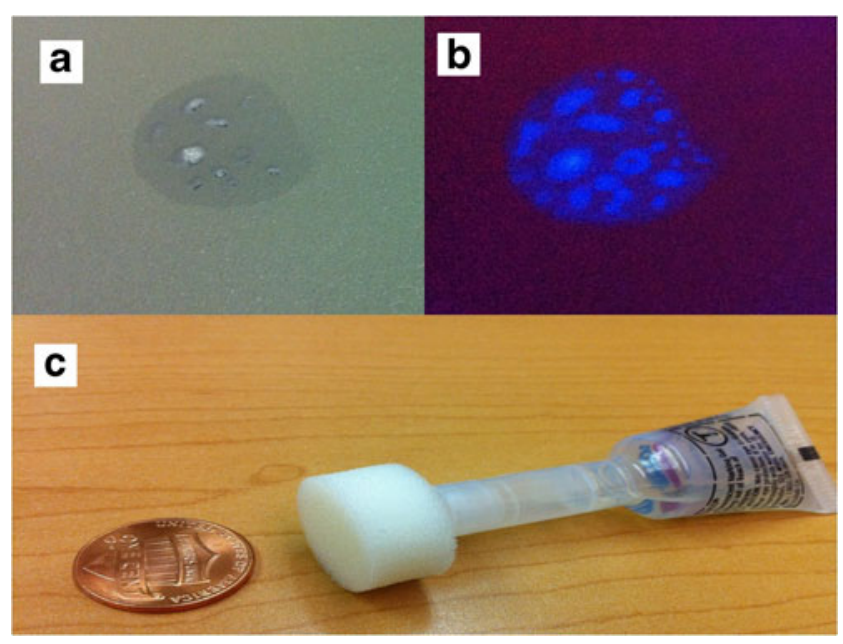

Fig. 3 Ultraviolet gel used to monitor environmental cleaning $(A)$ Ultraviolet marker under ambient light; $(B)$ ultraviolet marker under ultraviolet light; $(C)$ ultraviolet gel

[99]. Only $22 \%$ of 577 ultraviolet marks were removed (cleaned). The same group performed environmental cultures, although only looking for MRSA, finding $16 \%$ of surfaces cultured positive for this organism. The rate of surface positivity in each particular nursing home was associated with the prevalence of MRSA among residents and time spent cleaning the rooms. Interestingly, infection control practices at these nursing homes were not associated with the degree of surface positivity for MRSA [99].

At this time, data on the degree of environmental contamination at LTCFs with multidrug resistant Gramnegative organisms is lacking. Further research is necessary to determine the effect of heightened environmental disinfection on the patient-to-patient transmission of Gram-negatives in LTCFs.

\section{Role of Antimicrobial Stewardship Programs in Reducing Acquisitions of Multidrug Resistant Gram-Negative Organisms}

The IDSA defines stewardship as "coordinated interventions designed to improve and measure the appropriate use of antimicrobial agents by promoting the selection of the optimal antimicrobial drug regimen, including dosing, duration of therapy, and route of administration" [100]. The primary goal of stewardship is to maximize clinical outcomes while minimizing unintended consequences (e.g. emergence of resistance). Stewardship programs prevent the emergence of resistant Gram-negatives among patients, by reducing selective pressure [101-103]. Furthermore, establishing these programs in every healthcare facility, including LTCFs, is now recommended, and even mandated and regulated in many countries
[104, 105]; although, translating this into common practices has been proven challenging $[100,106]$.

Antibiotics are frequently misused among older adults. In a point survey analysis conducted in Australia, the prevalence and appropriateness of antibiotic use was studied among 257 residents of residential aged care facilities [107]. The age of $28 \%$ of the residents that were surveyed was greater than 85 years and $71 \%$ had been in these facilities for more than a year. Sixty-seven percent were incontinent, and $80 \%$ had some degree of cognitive impairment. Among the residents, 23 (9\%) were receiving antibiotics at the time of the survey: 17 were prescribed antibiotics for treatment of active infections, while six were given prophylactic antibiotics. During the preceding 26 months, there were 988 antibiotic courses administered; of these, $392(39.7 \%)$ did not fulfill the criteria for bacterial infection. This high antimicrobial utilization-frequently unwarranted - is what makes stewardship programs fundamental in both acute-care and LTCFs [107]; the latter is particularly important, given that residents at LTCFs might already be colonized with multidrug resistant Gram-negative organisms $[3,9,52 \bullet \bullet, 78,82 \bullet, 107,108]$.

Hospitals and LTCFs that implemented stewardship programs have experienced improved outcomes such as reduced antibiotic consumption, decreased rates of Clostridium difficile infection rates, reduced overall expenditures for antibiotic treatment, reduced overall healthcarerelated costs, decreased length of antibiotic therapy for various syndromes (e.g. community-acquired pneumonia), reductions in rates of inappropriate antimicrobial therapy, reductions in delays of initiation of appropriate therapy, and fewer antibiotic adverse events [109-115, $116 \bullet, 117-119,120 \bullet \bullet, 121]$. Several studies focused on the impact of implementation of antibiotic stewardship programs on acquisition of multidrug resistant Gram-negative organisms, but none measured the impact specifically among elderly adults [122].

There are numerous reports of interventions conducted at various types of LTCFs in order to reduce the rate of new MDRO acquisitions $[6 \bullet \bullet, 27,116 \bullet \bullet, 123-126,127 \bullet$, 128-130, 131•, 132-135]. Many were conducted in nursing homes consisting primarily of older adults [136•, 137, 138]. Some of the interventions were conducted as part of an outbreak investigation $[16,27]$ and some were conducted in order to decrease the endemicity and basal rate of acquisition of these deadly pathogens [116••]. Part of these interventions was establishment and implementation of a comprehensive stewardship program. Despite the fact that the direct impact of these programs on acquisition of MDROs among elderly has not yet been quantified, there is no reason to assume that the observed positive impact on the general population $[115,139]$, and LTCF residents $[16,116 \bullet \bullet, 118,120 \bullet \bullet, 123,124,126,133,136 \bullet, 137]$, would not also be seen among the elderly. 


\section{Conclusions}

The prevalence of multidrug resistant Gram-negative organisms is increasing worldwide. Elderly patients constitute important epidemiological links due to their frequent admissions and transfers across different healthcare facilities within a region. In addition, elderly patients are subjected to worse outcomes following the acquisition of multidrug resistant Gram-negative organisms. Given that LTCFs concentrate this type of patient population, more emphasis should be placed on implementing interventions targeting antimicrobial stewardship programs, hand hygiene among the staff, improving transitions of care (with better communication and documentation of colonization status) and environmental disinfection practices.

\section{Compliance with Ethics Guidelines}

Conflict of Interest Dror Marchaim has received payment for lectures, including service on speakers bureaus from MSD.

David E. Katz declares that he has no conflict of interest.

L. Silvia Muñoz-Price has received payment for lectures, including service on speakers bureaus from STERIS Corporation and Sage Products LLC.

Human and Animal Rights and Informed Consent This article does not contain any studies with human or animal subjects performed by any of the authors.

\section{References}

Papers of particular interest, published recently, have been highlighted as:

- Of importance

-. Of major importance

1. Boucher HW, Talbot GH, Bradley JS, et al. Bad bugs, no drugs: no ESKAPE! An update from the Infectious Diseases Society of America. Clin Infect Dis. 2009;48(1):1-12.

2. Marchaim D, Perez F, Lee J, et al. "Swimming in resistance": Cocolonization with carbapenem-resistant Enterobacteriaceae and Acinetobacter baumannii or Pseudomonas aeruginosa. Am J Infect Control. 2012;40(9):830-5.

3. Sengstock DM, Thyagarajan R, Apalara J, Mira A, Chopra T, Kaye KS. Multidrug-resistant Acinetobacter baumannii: an emerging pathogen among older adults in community hospitals and nursing homes. Clin Infect Dis. 2010;50(12):1611-6.

4. Schwaber MJ, Carmeli Y. Carbapenem-resistant Enterobacteriaceae: a potential threat. JAMA. 2008;300(24):2911-3.

5. Ben-Ami R, Schwaber MJ, Navon-Venezia S, et al. Influx of extended-spectrum beta-lactamase-producing enterobacteriaceae into the hospital. Clin Infect Dis. 2006;42(7):925-34.

6. •- Won SY, Munoz-Price LS, Lolans K, Hota B, Weinstein RA, Hayden MK. Emergence and rapid regional spread of Klebsiella pneumoniae carbapenemase-producing Enterobacteriaceae. Clin Infect Dis. 2011;53(6):532-40. This paper deals with the regional spread of resistant Gram-negative organisms. The epicenter of this outbreak was located in a long-term acute care hospital. Long-term care facilities of the area were also implicated.

7. Peleg AY, Hooper DC. Hospital-acquired infections due to gramnegative bacteria. N Engl J Med. 2010;362(19):1804-13.

8. Chopra T, Marchaim D, Prout A, et al. Epidemiology and Outcomes of Multidrug-resistant (MDR) Gram Negative Infections (GNIs) in Older Adults-A Large Multicenter Cohort Study. Washington: The American Geriatrics Society (AGS) 2011 Annual Scientific Meeting; 2011.

9. Marchaim D, Chopra T, Bogan C, et al. The burden of multidrugresistant organisms on tertiary hospitals posed by patients with recent stays in long-term acute care facilities. Am J Infect Control. 2012;40(8):760-5.

10. Munoz-Price LS. Long-term acute care hospitals. Clin Infect Dis. 2009;49(3):438-43.

11. Edwards JR, Peterson KD, Andrus ML, Dudeck MA, Pollock DA, Horan TC. National Healthcare Safety Network (NHSN) Report, data summary for 2006 through 2007, issued November 2008. Am J Infect Control. 2008;36(9):609-26.

12. Rosenthal VD, Bijie H, Maki DG, et al. International Nosocomial Infection Control Consortium (INICC) report, data summary of 36 countries, for 2004-2009. Am J Infect Control. 2012;40(5):396-407.

13. Livermore DM. Has the era of untreatable infections arrived? J Antimicrob Chemother. 2009;64 Suppl 1:i29-36.

14. Cosgrove SE. The relationship between antimicrobial resistance and patient outcomes: mortality, length of hospital stay, and health care costs. Clin Infect Dis. 2006;42 Suppl 2:S82-9.

15. Bonomo RA, Rossolini GM. Importance of antibiotic resistance and resistance mechanisms. Foreword Expert Rev Anti Infect Ther. 2008;6(5):549-50.

16. Munoz-Price LS, Hayden MK. Lolans K, et al. Successful control of an outbreak of Klebsiella pneumoniae carbapenemaseproducing $\mathrm{K}$ pneumoniae at a long-term acute care hospital Infect Control Hosp Epidemiol. 2010;31(4):341-7.

17. Parker CM, Kutsogiannis J, Muscedere J, et al. Ventilatorassociated pneumonia caused by multidrug-resistant organisms or Pseudomonas aeruginosa: prevalence, incidence, risk factors, and outcomes. J Crit Care. 2008;23(1):18-26.

18. Daniels TL, Deppen S, Arbogast PG, Griffin MR, Schaffner W, Talbot TR. Mortality rates associated with multidrug-resistant Acinetobacter baumannii infection in surgical intensive care units. Infect Control Hosp Epidemiol. 2008;29(11):1080-3.

19. Abbo A, Navon-Venezia S, Hammer-Muntz O, Krichali T, Siegman-Igra Y, Carmeli Y. Multidrug-resistant Acinetobacter baumannii. Emerg Infect Dis. 2005;11(1):22-9.

20. Aloush V, Navon-Venezia S, Seigman-Igra Y, Cabili S, Carmeli Y. Multidrug-resistant Pseudomonas aeruginosa: risk factors and clinical impact. Antimicrob Agents Chemother. 2006;50(1):43-8.

21. Munoz-Price LS, Weinstein RA. Acinetobacter infection. N Engl J Med. 2008;358(12):1271-81.

22. Navon-Venezia S, Ben-Ami R, Carmeli Y. Update on Pseudomonas aeruginosa and Acinetobacter baumannii infections in the healthcare setting. Curr Opin Infect Dis. 2005;18(4):306-13.

23. Edwards JR, Peterson KD, Mu Y, et al. National Healthcare Safety Network (NHSN) report: data summary for 2006 through 2008, issued December 2009. Am J Infect Control. 2009;37(10):783-805.

24. Gasink LB, Fishman NO, Nachamkin I, Bilker WB, Lautenbach E. Risk factors for and impact of infection or colonization with aztreonam-resistant Pseudomonas aeruginosa. Infect Control Hosp Epidemiol. 2007;28(10):1175-80.

25. Lautenbach E, Weiner MG, Nachamkin I, Bilker WB, Sheridan A, Fishman NO. Imipenem resistance among pseudomonas aeruginosa isolates: risk factors for infection and impact of resistance on clinical and economic outcomes. Infect Control Hosp Epidemiol. 2006;27(9):893-900.

26. Reddy T, Chopra T, Marchaim D, et al. Trends in antimicrobial resistance of Acinetobacter baumannii isolates from a metropolitan 
Detroit health system. Antimicrob Agents Chemother. 2010;54(5): 2235-8.

27. Munoz-Price LS, De La Cuesta C, Adams S, et al. Successful eradication of a monoclonal strain of Klebsiella pneumoniae during a K. pneumoniae carbapenemase-producing $\mathrm{K}$. pneumoniae outbreak in a surgical intensive care unit in Miami, Florida. Infect Control Hosp Epidemiol. 2010;31(10):1074-7.

28. Pogue JM, Lee J, Marchaim D, et al. Incidence of and risk factors for colistin-associated nephrotoxicity in a large academic health system. Clin Infect Dis. 2011;53(9):879-84.

29. Ku K, Pogue JM, Moshos J, et al. Retrospective evaluation of colistin versus tigecycline for the treatment of Acinetobacter baumannii and/or carbapenem-resistant Enterobacteriaceae infections. Am J Infect Control. 2012;40(10):983-7.

30. Yahav D, Lador A, Paul M, Leibovici L. Efficacy and safety of tigecycline: a systematic review and meta-analysis. J Antimicrob Chemother. 2011;66(9):1963-71.

31. Navon-Venezia S, Leavitt A, Carmeli Y. High tigecycline resistance in multidrug-resistant Acinetobacter baumannii. J Antimicrob Chemother. 2007;59(4):772-4.

32. Gilad J, Carmeli Y. Treatment options for multidrug-resistant Acinetobacter species. Drugs. 2008;68(2):165-89.

33. Fishbain J, Peleg AY. Treatment of Acinetobacter infections. Clin Infect Dis. 2010;51(1):79-84.

34. Pitout JD, Laupland KB. Extended-spectrum beta-lactamaseproducing Enterobacteriaceae: an emerging public-health concern. Lancet Infect Dis. 2008;8(3):159-66.

35. Marchaim D, Gottesman T, Schwartz O, et al. National multicenter study of predictors and outcomes of bacteremia upon hospital admission caused by Enterobacteriaceae producing extendedspectrum beta-lactamases. Antimicrob Agents Chemother. 2010;54(12):5099-104.

36. Rodriguez-Bano J, Alcala J, Cisneros JM, et al. Escherichia coli producing SHV-type extended-spectrum beta-lactamase is a significant cause of community-acquired infection. J Antimicrob Chemother. 2009;63(4):781-4.

37. Rodriguez-Bano J, Alcala JC, Cisneros JM, et al. Community infections caused by extended-spectrum beta-lactamase-producing Escherichia coli. Arch Intern Med. 2008;168(17):1897-902.

38. Rodriguez-Bano J, Navarro MD, Romero L, et al. Bacteremia due to extended-spectrum beta -lactamase-producing Escherichia coli in the CTX-M era: a new clinical challenge. Clin Infect Dis. 2006;43(11):1407-14.

39. Collins VL, Marchaim D, Pogue JM, et al. Efficacy of ertapenem for treatment of bloodstream infections caused by extendedspectrum-beta-lactamase-producing Enterobacteriaceae. Antimicrob Agents Chemother. 2012;56(4):2173-7.

40. Balkhed AO, Tarnberg M, Monstein HJ, Hallgren A, Hanberger H, Nilsson LE. High frequency of co-resistance in CTX-M-producing Escherichia coli to non-beta-lactam antibiotics, with the exceptions of amikacin, nitrofurantoin, colistin, tigecycline, and fosfomycin, in a county of Sweden. Scand J Infect Dis. 2013;45(4):271-8.

41. Auer S, Wojna A, Hell M. Oral treatment options for ambulatory patients with urinary tract infections caused by extendedspectrum-beta-lactamase-producing Escherichia coli. Antimicrob Agents Chemother. 2010;54(9):4006-8.

42. - Neuner EA, Sekeres J, Hall GS, van Duin D. Experience with fosfomycin for treatment of urinary tract infections due to multidrug-resistant organisms. Antimicrob Agents Chemother. 2012;56(11):5744-8. Fosfomycin might be a viable alternative for the treatment of urinary tract infections caused by multidrug resistant Gram-negatives.

43. Falagas ME, Kastoris AC, Kapaskelis AM, Karageorgopoulos DE. Fosfomycin for the treatment of multidrug-resistant, including extended-spectrum beta-lactamase producing, Enterobacteriaceae infections: a systematic review. Lancet Infect Dis. 2010;10(1):43-50.
44. •• Rodriguez-Bano J, Navarro MD, Retamar P, Picon E, Pascual A. beta-Lactam/beta-lactam inhibitor combinations for the treatment of bacteremia due to extended-spectrum beta-lactamaseproducing Escherichia coli: a post hoc analysis of prospective cohorts. Clin Infect Dis. 2012;54(2):167-74. This post-hoc analysis was performed among patients with bloodstream infections caused by ESBL-producing E. coli. The authors compared empirical and definitive antibiotic treatment with either a beta-lactam/ beta-lactamase inhibitor combination or a carbapenem. No differences were found in mortality nor length of stay.

45. Vardakas KZ, Tansarli GS, Rafailidis PI, Falagas ME. Carbapenems versus alternative antibiotics for the treatment of bacteraemia due to Enterobacteriaceae producing extended-spectrum betalactamases: a systematic review and meta-analysis. J Antimicrob Chemother. 2012;67(12):2793-803.

46. Gasink LB, Edelstein PH, Lautenbach E, Synnestvedt M. Fishman NO. Risk factors and clinical impact of Klebsiella pneumoniae carbapenemase-producing $\mathrm{K}$ pneumoniae Infect Control Hosp Epidemiol. 2009;30(12):1180-5.

47. Marchaim D, Chopra T, Bhargava A, et al. Recent exposure to antimicrobials and carbapenem-resistant Enterobacteriaceae: the role of antimicrobial stewardship. Infect Control Hosp Epidemiol. 2012;33(8):817-30.

48. Schwaber MJ, Klarfeld-Lidji S, Navon-Venezia S, Schwartz D, Leavitt A, Carmeli Y. Predictors of carbapenem-resistant Klebsiella pneumoniae acquisition among hospitalized adults and effect of acquisition on mortality. Antimicrob Agents Chemother. 2008;52(3):1028-33.

49. Giamarellou H, Poulakou G. Multidrug-resistant Gram-negative infections: what are the treatment options? Drugs. 2009;69(14):1879-901.

50. Hirsch EB, Tam VH. Detection and treatment options for Klebsiella pneumoniae carbapenemases (KPCs): an emerging cause of multidrug-resistant infection. J Antimicrob Chemother. 2010;65(6):1119-25.

51. Borer A, Saidel-Odes L, Riesenberg K, et al. Attributable mortality rate for carbapenem-resistant Klebsiella pneumoniae bacteremia. Infect Control Hosp Epidemiol. 2009;30(10):972-6.

52. • Schwaber MJ, Lev B, Israeli A, et al. ontainment of a countrywide outbreak of carbapenem-resistant Klebsiella pneumoniae in Israeli hospitals via a nationally implemented intervention. Clin Infect Dis. 2011;52(7):848-55. This study describes the Israeli experience of controlling a nation-wide outbreak of KPC-producing Klebsiella pneumoniae.

53. Kitchel B, Rasheed JK, Patel JB, et al. Molecular epidemiology of KPC-producing Klebsiella pneumoniae isolates in the United States: clonal expansion of multilocus sequence type 258 . Antimicrob Agents Chemother. 2009;53(8):3365-70.

54. Cuzon G, Naas T, Truong H, et al. Worldwide diversity of Klebsiella pneumoniae that produce beta-lactamase blaKPC-2 gene. Emerg Infect Dis. 2010;16(9):1349-56.

55. Guidance for control of infections with carbapenem-resistant or carbapenemase-producing Enterobacteriaceae in acute care facilities. MMWR Morb Mortal Wkly Rep 2009;58(10):256-60.

56. Marchaim D, Navon-Venezia S, Schwaber MJ, Carmeli Y. Isolation of imipenem-resistant Enterobacter species: emergence of KPC-2 carbapenemase, molecular characterization, epidemiology, and outcomes. Antimicrob Agents Chemother. 2008;52(4):1413-8.

57. Davies TA, Marie Queenan A, Morrow BJ, et al. Longitudinal survey of carbapenem resistance and resistance mechanisms in Enterobacteriaceae and non-fermenters from the USA in 2007-09. J Antimicrob Chemother. 2011;66(10):2298-307.

58. Kumarasamy KK, Toleman MA, Walsh TR, et al. Emergence of a new antibiotic resistance mechanism in India, Pakistan, and the UK: a molecular, biological, and epidemiological study. Lancet Infect Dis. 2010;10(9):597-602. 
59. Marra A. NDM-1: a local clone emerges with worldwide aspirations. Future Microbiol. 2011;6(2):137-41.

60. Lautenbach E, Marsicano R, Tolomeo P, Heard M, Serrano S, Stieritz DD. Epidemiology of antimicrobial resistance among gram-negative organisms recovered from patients in a multistate network of longterm care facilities. Infect Control Hosp Epidemiol. 2009;30(8):790-3.

61. Safdar N, Maki DG. The commonality of risk factors for nosocomial colonization and infection with antimicrobial-resistant Staphylococcus aureus, enterococcus, gram-negative bacilli, Clostridium difficile, and Candida. Ann Intern Med. 2002;136(11):834-44.

62. Lautenbach E, Synnestvedt M, Weiner MG, et al. Imipenem resistance in Pseudomonas aeruginosa: emergence, epidemiology, and impact on clinical and economic outcomes. Infect Control Hosp Epidemiol. 2010;31(1):47-53.

63. Mueller MR, Hayden MK, Fridkin SK, et al. Nosocomial acquisition of Pseudomonas aeruginosa resistant to both ciprofloxacin and imipenem: a risk factor and laboratory analysis. Eur J Clin Microbiol Infect Dis. 2008;27(7):565-70.

64. Defez C, Fabbro-Peray P, Bouziges N, et al. Risk factors for multidrug-resistant Pseudomonas aeruginosa nosocomial infection. J Hosp Infect. 2004;57(3):209-16.

65. Pappas G, Saplaoura K, Falagas ME. Current treatment of pseudomonal infections in the elderly. Drugs Aging. 2009;26(5):363-79.

66. Lautenbach E, Synnestvedt M, Weiner MG, et al. Epidemiology and impact of imipenem resistance in Acinetobacter baumannii. Infect Control Hosp Epidemiol. 2009;30(12):1186-92.

67. Brahmi N, Beji O, Abidi N, et al. Epidemiology and risk factors for colonization and infection by Acinetobacter baumannii in an ICU in Tunisia, where this pathogen is endemic. J Infect Chemother. 2007;13(6):400-4.

68. Park SY, Kang CI, Joo EJ, et al. Risk factors for multidrug resistance in nosocomial bacteremia caused by extendedspectrum beta-lactamase-producing Escherichia coli and Klebsiella pneumoniae. Microb Drug Resist. 2012;18(5):518-24.

69. Antoniadou A, Kontopidou F, Poulakou G, et al. Colistin-resistant isolates of Klebsiella pneumoniae emerging in intensive care unit patients: first report of a multiclonal cluster. J Antimicrob Chemother. 2007;59(4):786-90.

70. Charlson ME, Pompei P, Ales KL, MacKenzie CR. A new method of classifying prognostic comorbidity in longitudinal studies: development and validation. J Chronic Dis. 1987;40(5):373-83.

71. Bion JF, Edlin SA, Ramsay G, McCabe S, Ledingham IM. Validation of a prognostic score in critically ill patients undergoing transport. Br Med J (Clin Res Ed). 1985;291(6493):432-4.

72. Kollmann TR, Levy O, Montgomery RR, Goriely S. Innate immune function by Toll-like receptors: distinct responses in newborns and the elderly. Immunity. 2012;37(5):771-83.

73. Lambert ND, Ovsyannikova IG, Pankratz VS, Jacobson RM, Poland GA. Understanding the immune response to seasonal influenza vaccination in older adults: a systems biology approach. Expert Rev Vaccines. 2012;11(8):985-94.

74. Dewan SK, Zheng SB, Xia SJ, Bill K. Senescent remodeling of the immune system and its contribution to the predisposition of the elderly to infections. Chin Med J (Engl). 2012;125(18):3325-31.

75. Meyer C, Kerns A, Haberthur K, Messaoudi I. Improving immunity in the elderly: current and future lessons from nonhuman primate models. Age (Dordr). 2012;34(5):1157-68.

76. Girard TD, Ely EW. Bacteremia and sepsis in older adults. Clin Geriatr Med. 2007;23(3):633-47. viii.

77. Leibovici L, Pitlik SD, Konisberger H, Drucker M. Bloodstream infections in patients older than eighty years. Age Ageing. 1993;22(6):431-42.

78. Ben-Ami R, Rodriguez-Bano J, Arslan H, et al. A multinational survey of risk factors for infection with extended-spectrum betalactamase-producing enterobacteriaceae in nonhospitalized patients. Clin Infect Dis. 2009;49(5):682-90.
79. Mody L. Infection control issues in older adults. Clin Geriatr Med. 2007;23(3):499-514. vi.

80. - Montoya A, Mody L. Common infections in nursing homes: a review of current issues and challenges. Aging health. 2011;7(6):889-99. This is a comprenhensive review of the infection control challanges in long-term care facilities.

81. Nicolle LE. Antimicrobial resistance in long-term care facilities. Future Microbiol. 2012;7(2):171-4.

82. - Ben-David D, Masarwa S, Navon-Venezia S, et al. Carbapenemresistant Klebsiella pneumoniae in post-acute-care facilities in Israel. Infect Control Hosp Epidemiol. 2011;32(9):845-53. Epidemiological paper describing the high prevalence of KPC-producing Enterobacteriaceae among long-term care facility residents in Israel.

83. Smith PW, Bennett G, Bradley S, et al. SHEA/APIC guideline: infection prevention and control in the long-term care facility, July 2008. Infect Control Hosp Epidemiol. 2008;29(9):785-814.

84. Castle NG, Wagner LM, Ferguson-Rome JC, Men A, Handler SM. Nursing home deficiency citations for infection control. Am J Infect Control. 2011;39(4):263-9.

85. Abad C, Fearday A, Safdar N. Adverse effects of isolation in hospitalised patients: a systematic review. J Hosp Infect. 2010;76(2):97-102.

86. Stelfox HT, Bates DW, Redelmeier DA. Safety of patients isolated for infection control. JAMA. 2003;290(14):1899-905.

87. Trick WE, Weinstein RA, DeMarais PL, et al. Comparison of routine glove use and contact-isolation precautions to prevent transmission of multidrug-resistant bacteria in a long-term care facility. J Am Geriatr Soc. 2004;52(12):2003-9.

88. Mody L, Bradley SF, Galecki A, et al. Conceptual model for reducing infections and antimicrobial resistance in skilled nursing facilities: focusing on residents with indwelling devices. Clin Infect Dis. 2011;52(5):654-61.

89. Pittet D, Allegranzi B, Sax H, et al. Evidence-based model for hand transmission during patient care and the role of improved practices. Lancet Infect Dis. 2006;6(10):641-52.

90. Smith A, Carusone SC, Loeb M. Hand hygiene practices of health care workers in long-term care facilities. Am J Infect Control. 2008;36(7):492-4.

91. Pan A, Domenighini F, Signorini L, et al. Adherence to hand hygiene in an Italian long-term care facility. Am J Infect Control. 2008;36(7):495-7.

92. Mody L, McNeil SA, Sun R, Bradley SE, Kauffman CA. Introduction of a waterless alcohol-based hand rub in a long-term-care facility. Infect Control Hosp Epidemiol. 2003;24(3):165-71.

93. Ashraf MS, Hussain SW, Agarwal N, et al. Hand hygiene in longterm care facilities: a multicenter study of knowledge, attitudes, practices, and barriers. Infect Control Hosp Epidemiol. 2010;31(7):758-62.

94. Spector W, Mutter R, Owens P, Limcangco R. STATISTICAL BRIEF \#141; Transitions between Nursing Homes and Hospitals in the Elderly Population, 2009. Healthcare Cost and Utilization Project (HCUP) Sponsored by the Agency for Healthcare Research and Quality (AHRQ), 2012.

95. Ho CH, Johnson T, Miklacic J, Donskey CJ. Is the use of lowpressure pulsatile lavage for pressure ulcer management associated with environmental contamination with Acinetobacter baumannii? Arch Phys Med Rehabil. 2009;90(10):1723-6.

96. Strassle P, Thom KA, Johnsonm JK, et al. The effect of terminal cleaning on environmental contamination rates of multidrugresistant Acinetobacter baumannii. Am J Infect Control. 2012;40(10):1005-7.

97. Munoz-Price LS, Ariza-Heredia E, Adams S, et al. Use of UV powder for surveillance to improve environmental cleaning. Infect Control Hosp Epidemiol. 2011;32(3):283-5.

98. Carling PC, Parry MF, Bruno-Murtha LA, Dick B. Improving environmental hygiene in 27 intensive care units to decrease 
multidrug-resistant bacterial transmission. Crit Care Med. 2010;38(4):1054-9.

99. Murphy CR, Eells SJ, Quan V, et al. Methicillin-resistant Staphylococcus aureus burden in nursing homes associated with environmental contamination of common areas. J Am Geriatr Soc. 2012;60(6):1012-8.

100. Policy statement on antimicrobial stewardship by the Society for Healthcare Epidemiology of America (SHEA), the Infectious Diseases Society of America (IDSA), and the Pediatric Infectious Diseases Society (PIDS). Infect Control Hosp Epidemiol 2012;33(4):322-7.

101. Cosgrove SE, Patel A, Song X, et al. Impact of different methods of feedback to clinicians after postprescription antimicrobial review based on the Centers For Disease Control and Prevention's 12 Steps to Prevent Antimicrobial Resistance Among Hospitalized Adults. Infect Control Hosp Epidemiol. 2007;28(6):641-6.

102. Dellit TH, Owens RC, McGowan Jr JE, et al. Infectious Diseases Society of America and the Society for Healthcare Epidemiology of America guidelines for developing an institutional program to enhance antimicrobial stewardship. Clin Infect Dis. 2007;44(2):159-77.

103. Graf K, Sohr D, Haverich A, Kuhn C, Gastmeier P, Chaberny IF. Decrease of deep sternal surgical site infection rates after cardiac surgery by a comprehensive infection control program. Interact Cardiovasc Thorac Surg. 2009;9(2):282-6.

104. Tamma PD, Cosgrove SE. Antimicrobial stewardship. Infect Dis Clin North Am. 2011;25(1):245-60.

105. Donlon S, Roche F, Byrne H, Dowling S, Cotter M, Fitzpatrick F. A national survey of infection control and antimicrobial stewardship structures in Irish long-term care facilities. Am J Infect Control. 2013;41(6):554-7.

106. Buising KL, Thursky KA, Robertson MB, et al. Electronic antibiotic stewardship-reduced consumption of broad-spectrum antibiotics using a computerized antimicrobial approval system in a hospital setting. J Antimicrob Chemother. 2008;62(3):608-16.

107. Stuart RL, Wilson J, Bellaard-Smith E, et al. Antibiotic use and misuse in residential aged care facilities. Intern Med J. 2012;42(10):1145-9.

108. Schwaber MJ, Masarwa S, Navon-Venezia S, et al. High prevalence of methicillin-resistant Staphylococcus aureus among residents and staff of long-term care facilities, involving joint and parallel evolution. Clin Infect Dis. 2011;53(9):910-3.

109. Carling P, Fung T, Killion A, Terrin N, Barza M. Favorable impact of a multidisciplinary antibiotic management program conducted during 7 years. Infect Control Hosp Epidemiol. 2003;24(9):699-706.

110. Ruttimann S, Keck B, Hartmeier C, Maetzel A, Bucher HC. Longterm antibiotic cost savings from a comprehensive intervention program in a medical department of a university-affiliated teaching hospital. Clin Infect Dis. 2004;38(3):348-56.

111. Avdic E, Cushinotto LA, Hughes AH, et al. Impact of an antimicrobial stewardship intervention on shortening the duration of therapy for community-acquired pneumonia. Clin Infect Dis. 2012;54(11):1581-7.

112. Kaki R, Elligsen M, Walker S, Simor A, Palmay L, Daneman N. Impact of antimicrobial stewardship in critical care: a systematic review. J Antimicrob Chemother. 2011;66(6):1223-30.

113. Fishman N. Antimicrobial stewardship. Am J Infect Control 2006;34(5 Suppl 1):S55-63; discussion S4-73.

114. Carmeli Y, Akova M, Cornaglia G, et al. Controlling the spread of carbapenemase-producing Gram-negatives: therapeutic approach and infection control. Clin Microbiol Infect. 2010;16(2):102-11.

115. Dortch MJ, Fleming SB, Kauffmann RM, Dossett LA, Talbot TR, May AK. Infection reduction strategies including antibiotic stewardship protocols in surgical and trauma intensive care units are associated with reduced resistant gram-negative healthcareassociated infections. Surg Infect (Larchmt). 2011;12(1):15-25.

116. •- Jump RL, Olds DM, Seifi N, et al. Effective antimicrobial stewardship in a long-term care facility through an infectious disease consultation service: keeping a LID on antibiotic use. Infect Control Hosp Epidemiol. 2012;33(12):1185-92. Infectious Diseases specialists were succesful reducing by $30 \%$ the administration of antibiotics at a long-term care facility.

117. Dubrovskaya Y, Papadopoulos J, Scipione MR, Altshuler J, Phillips M, Mehta SA. Antibiotic stewardship for intra-abdominal infections: early impact on antimicrobial use and patient outcomes. Infect Control Hosp Epidemiol. 2012;33(4):427-9.

118. Slekovec C, Leroy J, Vernaz-Hegi N, et al. Impact of a region wide antimicrobial stewardship guideline on urinary tract infection prescription patterns. Int J Clin Pharm. 2012;34(2):325-9.

119. Sharma M, Eriksson B, Marrone G, Dhaneria S, Lundborg CS. Antibiotic prescribing in two private sector hospitals; one teaching and one non-teaching: a cross-sectional study in Ujjain. India BMC Infect Dis. 2012;12:155.

120. •• Pate PG, Storey DF, Baum DL. Implementation of an antimicrobial stewardship program at a 60-bed long-term acute care hospital. Infect Control Hosp Epidemiol. 2012;33(4):405-8. An antimicrobial stewardship program was succesful decreasing the antibiotic use by $21 \%$ reduction in use while reducing the cost per patient-day by $28 \%$.

121. Nowak MA, Nelson RE, Breidenbach JL, Thompson PA, Carson PJ. Clinical and economic outcomes of a prospective antimicrobial stewardship program. Am J Health Syst Pharm. 2012;69(17):1500-8.

122. Carmeli Y, Akova M, Cornaglia G, et al. Controlling the spread of carbapenemase-producing Gram-negatives: therapeutic approach and infection control. Clin Microbiol Infect. 2010;16(2):102-11.

123. Goldstein EJ, Polonsky J, Touzani M, Citron DM. C. difficile infection (CDI) in a long-term acute care facility (LTAC). Anaerobe. 2009; 15(6):241-3.

124. Furuno JP, Hebden JN, Standiford HC, et al. Prevalence of methicillinresistant Staphylococcus aureus and Acinetobacter baumannii in a long-term acute care facility. Am J Infect Control. 2008;36(7):468-71.

125. Stephens C, Francis SJ, Abell V, DiPersio JR, Wells P. Emergence of resistant Acinetobacter baumannii in critically ill patients within an acute care teaching hospital and a long-term acute care hospital. Am J Infect Control. 2007;35(4):212-5.

126. Ludwig A, Sato K, Schirmer P, et al. Concurrent outbreaks with co-infection of norovirus and Clostridium difficile in a long-termcare facility. Epidemiol Infect. 2013;22:1-6.

127. • Prabaker K, Lin MY, McNally M, et al. Transfer from high-acuity long-term care facilities is associated with carriage of Klebsiella pneumoniae carbapenemase-producing Enterobacteriaceae: a multihospital study. Infect Control Hosp Epidemiol. 2012;33(12):1193-9. Patients transferred from long-term acute care hospitals or long-term care facilities with ventilator care had higher likelihood of being colonized with KPC-producing Enterobacteriaceae than community controls.

128. Pawar D, Tsay R, Nelson DS, et al. Burden of Clostridium difficile infection in long-term care facilities in Monroe County. New York Infect Control Hosp Epidemiol. 2012;33(11):1107-12.

129. Parish A, Holliday K. Long-term care acquired urinary tract infections' antibiotic resistance patterns and empiric therapy: a pilot study. Geriatr Nurs. 2012;33(6):473-8.

130. Bilavsky E, Lerman Y, Rabinovich A, et al. Carriage of methicillin-resistant Staphylococcus aureus on admission to $\mathrm{Eu}-$ ropean rehabilitation centres-a prospective study. Clin Microbiol Infect. 2012;18(6):E164-9.

131. • Viau RA, Hujer AM, Marshall SH, et al. "Silent" dissemination of Klebsiella pneumoniae isolates bearing K. pneumoniae carbapenemase in a long-term care facility for children and young adults in Northeast Ohio. Clin Infect Dis. 2012;54(9):1314-21. Identification of bla ${ }_{K P C}$ in 12 stool isolates from long-term care facility patients, which were initially collected in 2004.

132. Perez F, Endimiani A, Ray AJ, et al. Carbapenem-resistant Acinetobacter baumannii and Klebsiella pneumoniae across a hospital system: impact of post-acute care facilities on dissemination. $\mathrm{J}$ Antimicrob Chemother. 2010;65(8):1807-18. 
133. Endimiani A, Depasquale JM, Forero S, et al. Emergence of blaKPC-containing Klebsiella pneumoniae in a long-term acute care hospital: a new challenge to our healthcare system. J Antimicrob Chemother. 2009;64(5):1102-10.

134. Rodriguez-Bano J, Garcia L, Ramirez E, et al. Long-term control of hospital-wide, endemic multidrug-resistant Acinetobacter baumannii through a comprehensive "bundle" approach. Am J Infect Control. 2009;37(9):715-22.

135. Debast SB, Vaessen N, Choudry A, Wiegers-Ligtvoet EA, van den Berg RJ, Kuijper EJ. Successful combat of an outbreak due to Clostridium difficile PCR ribotype 027 and recognition of specific risk factors. Clin Microbiol Infect. 2009;15(5):427-34.

136. - Daneman N, Gruneir A, Newman A, et al. Antibiotic use in longterm care facilities. J Antimicrob Chemother. 2011;66(12):285663. Point-prevalence study at long-term care facilities found 5.9 $\%$ of residents receiving antibiotic prescriptions on the study date. The three most common antibiotics were nitrofurantoin, trimethoprim/sulfamethoxazole, and ciprofloxacin.

137. Daneman N, Rochon P. Antimicrobial stewardship: opportunities in long-term care homes. Drugs Aging. 2011;28(10):765-7.

138. Hughes FA, Bamford A. Providing nursing leadership in a community residential mental health setting. J Psychosoc Nurs Ment Health Serv. 2011;49(7):35-42.

139. Yong MK, Buising KL, Cheng AC, Thursky KA. Improved susceptibility of Gram-negative bacteria in an intensive care unit following implementation of a computerized antibiotic decision support system. J Antimicrob Chemother. 2010;65(5):1062-9.

140. Magiorakos AP, Srinivasan A, Carey RB, et al. Multidrug-resistant, extensively drug-resistant and pandrug-resistant bacteria: an international expert proposal for interim standard definitions for acquired resistance. Clin Microbiol Infect. 2012;18(3):268-81.

141. Kaye KS, Cosgrove S, Harris A, Eliopoulos GM, Carmeli Y. Risk factors for emergence of resistance to broad-spectrum cephalosporins among Enterobacter spp. Antimicrob Agents Chemother. 2001;45(9):2628-30.

142. Marchaim D, Navon-Venezia S, Leavitt A, Chmelnitsky I, Schwaber MJ, Carmeli Y. Molecular and epidemiologic study of polyclonal outbreaks of multidrug-resistant Acinetobacter baumannii infection in an Israeli hospital. Infect Control Hosp Epidemiol. 2007;28(8):945-50.

143. Marchaim D, Navon-Venezia S, Schwartz D, et al. Surveillance cultures and duration of carriage of multidrug-resistant Acinetobacter baumannii. J Clin Microbiol. 2007;45(5):1551-5.

144. Peleg AY. Optimizing therapy for Acinetobacter baumannii. Semin Respir Crit Care Med. 2007;28(6):662-71.

145. Peleg AY, Seifert H, Paterson DL. Acinetobacter baumannii: emergence of a successful pathogen. Clin Microbiol Rev. 2008;21(3):538-82.

146. Pena C, Gomez-Zorrilla S, Suarez C, et al. Extensively drugresistant Pseudomonas aeruginosa: risk of bloodstream infection in hospitalized patients. Eur J Clin Microbiol Infect Dis. 2012;31(10):2791-7.

147. Paul M, Leibovici L. Combination Therapy for Pseudomonas aeruginosa Bacteremia: Where Do We Stand? Clin Infect Dis 2013 May 3 [Epub ahead of print].

148. van Duin D, Kaye KS, Neuner EA, Bonomo RA. Carbapenemresistant Enterobacteriaceae: a review of treatment and outcomes. Diagn Microbiol Infect Dis. 2013;75(2):115-20. 